\title{
Parent Health Literacy and "Obesogenic" Feeding and Physical Activity-related Infant Care Behaviors
}

\author{
H. Shonna Yin, MD, MS ${ }^{1}$, Lee M. Sanders, MD, MPH², Russell L. Rothman, MD, MPP ${ }^{3}$, \\ Rachel Shustak, BA ${ }^{1}$, Svetlana K. Eden, $\mathrm{MS}^{4}$, Ayumi Shintani, PhD, MPH ${ }^{4}$, Maria E. Cerra, \\ BA $^{1}$, Evelyn F. Cruzatte, BA ${ }^{1}$, and Eliana M. Perrin, MD, MPH $^{5}$ \\ ${ }^{1}$ Department of Pediatrics, NYU School of Medicine, New York, NY \\ ${ }^{2}$ Department of Pediatrics and Center for Health Policy, Stanford University, Stanford, CA \\ ${ }^{3}$ Departments of Internal Medicine and Pediatrics, Vanderbilt University Medical Center, \\ Nashville, TN \\ ${ }^{4}$ Department of Biostatistics, Vanderbilt University Medical Center, Nashville, TN \\ ${ }^{5}$ Department of Pediatrics, University of North Carolina at Chapel Hill School of Medicine and \\ Cecil G. Sheps Center for Health Services Research, Chapel Hill, NC
}

\begin{abstract}
Objective-To examine the relationship between parent health literacy and "obesogenic" infant care behaviors.
\end{abstract}

Study design-Cross-sectional analysis of baseline data from a cluster randomized controlled trial of a primary care-based, early childhood obesity prevention program (Greenlight). English and Spanish-speaking parents of 2 month old children enrolled $(n=844)$. The primary predictor variable was a parent health literacy (Short Test of Functional Health Literacy in Adults (STOFHLA); adequate $>=23$; low $<23$ ). Primary outcome variables involving self-reported obesogenic behaviors: (1) feeding content (more formula than breastmilk, sweet drinks, early solid food introduction) and feeding style-related behaviors (pressuring to finish, laissez-faire bottle propping/television [TV] watching while feeding, non-responsiveness in letting child decide amount to eat); and (2) physical activity (tummy time, TV). Multivariate logistic regression analyses (binary, proportional odds models) performed adjusting for child sex, out of home care, WIC status, parent age, race/ethnicity, language, number of adults/children in home, income, and site.

Results-11.0\% of parents were categorized as having low health literacy. Low health literacy significantly increased the odds of a parent reporting that they feed more formula than breast milk $(\mathrm{AOR}=2.0$ [95\%CI:1.2-3.5]), immediately feed when their child cries $(\mathrm{AOR}=1.8[1.1-2.8])$, bottle

\footnotetext{
(c) 2013 Mosby, Inc. All rights reserved.

CORRESPONDENCE: H. Shonna Yin, MD, MS, New York University School of Medicine, Department of Pediatrics, 550 First Avenue, NBV 8S4-11, New York, NY 10016, Telephone: (212) 562-2821; Fax: (212) 263-8172, yinh02@med.nyu.edu.

The authors declare no conflicts of interest.

Portions of this study were presented at the Health Literacy Annual Research Conference, October 18, 2012, Chicago, IL. Registered with ClinicalTrials.gov: NCT01040897

Publisher's Disclaimer: This is a PDF file of an unedited manuscript that has been accepted for publication. As a service to our customers we are providing this early version of the manuscript. The manuscript will undergo copyediting, typesetting, and review of the resulting proof before it is published in its final citable form. Please note that during the production process errors may be discovered which could affect the content, and all legal disclaimers that apply to the journal pertain.
} 
prop $(\mathrm{AOR}=1.8$ [1.002-3.1]), any infant TV watching ( $\mathrm{AOR}=1.8$ [1.1-3.0]), and inadequate tummy time ( $<30$ minutes/day) (AOR=3.0[1.5-5.8]).

Conclusions-Low parent health literacy is associated with certain obesogenic infant care behaviors. These behaviors may be modifiable targets for low health literacy-focused interventions to help reduce childhood obesity.

\section{Keywords}

obesity; parenting skills; feeding practices; feeding styles; physical activity; television

The prevalence of childhood obesity has been rising in the US, with rates nearly tripling since $1980 .{ }^{1}$ There is growing evidence that weight status during infancy may be predictive of obesity, cardiovascular disease, hypertension, and insulin resistance in adulthood. ${ }^{4,5}$

"Obesogenic" feeding behaviors have been proposed as modifiable targets for childhood obesity prevention. Potential obesogenic diet content-related practices include formula feeding ${ }^{6}$ provision of sweet drinks, ${ }^{7}$ and introduction of solid foods before four months of age. " "Controlling" feeding styles, including pressuring to feed, involve behaviors that overlook an infant's satiety cues. ${ }^{9}$ Children of mothers who are controlling, rather than responsive in their feeding, are less able to self-regulate energy intake. ${ }^{10}$ The link between childhood obesity and other feeding styles, such as a "laissez-faire" style, in which parents have limited infant interaction during feeding (e.g. bottle propping), and do not place limits on diet quality/quantity, has not been well-studied. ${ }^{11}$ Obesogenic physical activity practices may include excessive television (TV) viewing and inadequate time in the prone position while awake (ie, "tummy time"). ${ }^{1314}$

Low health literacy is associated with increased risk for adult obesity, ${ }^{15}, 16$ and low parent health literacy may be a risk factor for the development of early childhood obesity. ${ }^{17}$ Defined as the "degree to which individuals have the capacity to obtain, process, and understand basic health information and services needed to make appropriate health decisions," ${ }^{18}$ low parent health literacy has been independently associated with poor child health outcomes. ${ }^{16}$ Although few studies have assessed the association between health literacy and behaviors which may directly impact early childhood obesity, ${ }^{11}$ caregivers with low health literacy have been found to be less likely to breastfeed, ${ }^{19}$ have trouble understanding growth charts, ${ }^{20}$ and are more likely to have difficulty understanding food labels and portion sizes. ${ }^{17}$ As there has been limited study of the relationship between parent health literacy and obesogenic infant care behaviors, we sought to examine these associations in this study.

\section{METHODS}

This was a cross-sectional analysis of baseline data collected from caregiver-child dyads participating in the Greenlight study, a cluster randomized trial of a health literacy and numeracy-oriented health communication intervention to reduce obesogenic behaviors and prevent obesity in the first 2 years of life. Consecutive eligible caregiver-child dyads were enrolled from four university-affiliated pediatric continuity clinics (New York University/ Bellevue Hospital Center, Vanderbilt University, University of North Carolina-Chapel Hill, University of Miami). Inclusion criteria for caregiver-child dyads were: infant aged 6 to $<16$ weeks presenting for a 2-month well-child visit with a pediatric resident, and caregiver who was English or Spanish-speaking, who expected to return to the clinic for all well-child visits through 2 years of age. Child-related exclusion criteria were: $<34$ weeks gestation, birth weight $<1500$ grams, weight-for-length $<3^{\text {rd }}$ percentile at 2 month visit, or diagnosis of failure to thrive or other medical problem known to affect child growth (eg, cleft palate). 
Caregiver-related exclusion criteria were: age $<18$ years, mental/neurological illness, poor visual acuity (Rosenbaum worse than 20/50 corrected). Written and verbal informed consent was obtained from all participants. Institutional Review Board approval was obtained from the four participating academic medical centers. For the remainder of this paper, we refer to caregivers as parents, as $99 \%$ of the caregivers were parents.

Data were obtained by interview at the 2-month well-child visit (English or Spanish, parent preference). Data were managed with REDCap (Research Electronic Data Capture). ${ }^{21}$ The primary dependent variables of interest were parent report of obesogenic infant feeding and physical activity-related practices at the 2 month well-visit assessments.

Three obesogenic diet content-related practices were assessed: formula feeding, ${ }^{6}$ provision of sweet drinks ${ }^{7}$ and early introduction of solid foods. ${ }^{8}$ Formula feeding was assessed using the question, "What type of milk does your child drink now?," with answer choices of formula only, mostly formula and some breast milk (BM), equal formula and BM, mostly BM but some formula, and BM only. Answers were dichotomized in analyses, with those who fed more formula than BM compared with all others, as prior study has shown that infants fed more formula than breast milk in the first 6 months of life are at an increased risk for being overweight in adolescence. ${ }^{6}$ Provision of sweet drinks was assessed by asking the parent how much 100\% fruit juice, or other sweet drinks (fruit punch, fruit juice with added sugar, soda, sweet tea, lemonade, Gatorade, sugar water) the child usually drinks in a day, with answers dichotomized as a composite variable with any provision compared with none. Early introduction of solids was assessed using two questions. The first question was "Is your child eating solid foods yet or do you put any solid foods in the bottle?" with answer choices of yes and no. The second question, taken from the validated Infant Feeding Style Questionnaire (IFSQ), ${ }^{22}$ was "I give my baby cereal in the bottle." All IFSQ questions asked parents about the frequency of behaviors, with choices of always, most of the time, half of the time, seldom or infrequently, and never. An indication in either question that a solid was introduced met the criteria of any solid introduction.

Parent behaviors associated with obesogenic feeding styles were assessed with a subset of questions from the IFSQ. ${ }^{22}$ Behaviors considered to be controlling/pressuring, were assessed with statements: "I try to get my child to finish his or her breast milk or formula" and "When my baby cries, I immediately feed him or her." Behaviors considered to be laissezfaire were assessed with statements: "When my child has a bottle, I prop it up" and "I watch TV while feeding my baby." One aspect of responsive feeding was assessed: "I let my child decide how much to eat." Lack of responsiveness was considered obesogenic.

Two obesogenic physical-activity practices were assessed: TV viewing ${ }^{13}$ and inadequate tummy time. ${ }^{14}$ TV time was assessed with the question "How much time does [CHILD's NAME] spend watching television each day?". Based on the American Academy of Pediatrics (AAP) evidence-based practice guideline that infants not watch any television, ${ }^{23}$ $\mathrm{TV}$ viewing was dichotomized for our two month age cohort as any compared with none. Tummy time was assessed using the question, "How much total time does your child typically spend being active on his/her tummy while awake each day?" Based on existing recommendations, inadequate tummy time was defined as $<30$ minutes per day. ${ }^{14}$

The primary independent variable for this study was parent health literacy, assessed using the Short Test of Functional Health Literacy in Adults (STOFHLA) ${ }^{24}$ Health literacy was categorized as inadequate (score $0-16$ ), marginal (17-22), or adequate (23-36). The STOFHLA is one of the most commonly used health literacy assessments. ${ }^{25,}{ }^{26}$ For purposes of analyses, health literacy was a priori dichotomized as those with adequate health literacy compared with those with low (inadequate/marginal) health literacy. 
Child characteristics included child's age and sex, as well as out of home care (any or none), as child care outside of the home could affect both feeding and physical activity behaviors. Information on participation in WIC (yes or no) and child health insurance (Medicaid, private, none) was collected as these variables are indicators of access to counseling on child nutrition and activity. Parent characteristics included parent sex and age, as well as relationship to child (mother, father, other), country of origin (US-born or not), race/ ethnicity (Hispanic, or non-Hispanic White, Black or other), language (English, Spanish; interview language), and education (less than high school, high school graduate/equivalent, some college, college graduate or higher). Household characteristics included income (< $\$ 10,000, \$ 10,000-19,999, \$ 20,000-39,999, \$ 40,000+)$, number of adults ( $\geq 18$ years) $(1, \geq 2$ adults) and number of children ( $<18$ years) $(1, \geq 2$ children). Being a parent raising a child alone, as well as prior experience with raising children, are factors that may influence infant feeding and activity practices.

\section{Statistical Analyses}

Data were analyzed using R version 2.15 (www.r-project.org). For all analyses, a 2-tailed pvalue $<0.05$ was considered statistically significant. We assessed unadjusted associations between health literacy and the outcomes of interest, using Chi-square test and MannWhitney U tests for categorical, and Kruskal-Wallis test for ordinal outcomes. Adjusted analyses were performed using logistic regression for binary outcomes, and proportional odds logistic regression for ordinal categorical variables ("Gets child to finish," "Immediately feeds when baby cries," "Props bottle," "Watches TV while feeding," "Let's child decide how much to eat"). To prevent overfitting, ${ }^{27}$ these analyses controlled for an $a$ priori defined set of potential confounders: child sex, child out of home care, WIC status; parent age, race/ethnicity, language; household income, number of adults/children in the home, income; recruitment site. Parent age was modeled as a non-linear term, restricted cubic spline with 3 knots. ${ }^{27}$ Caregiver relationship to the child was not included in the model because $>95 \%$ of caregivers were mothers, and thus this variable would be unlikely to act as a confounder. Given ongoing debate about the relationship between education and health literacy, we analyzed models with and without education. ${ }^{28}$ Sensitivity analyses performed adjusting for child weight-for-length $\mathrm{z}$ score did not meaningfully alter the results of the analysis.

\section{RESULTS}

Between the enrollment period of April 28, 2010 and July 24, 2012, families presenting with their infant for a 2 month well-child visit were consecutively assessed (; available at www.jpeds.com). Data from 844 parent-child dyads were included in analyses (Table I). Mean (SD) parent STOFHLA score was 31.4 (7.8) (range=0-36). 11.0\% were categorized as low health literacy (7.8\% inadequate, $3.2 \%$ marginal).

In unadjusted analyses, parents with low health literacy were more likely to give formula most of the time (68.8 vs. 58.1\%, p=0.046). Parents with low health literacy also were more likely to pressure their child to feed by getting their child to finish $(\mathrm{p}=0.02)$ or by immediately feeding when infant cries $(\mathrm{p}<0.001)$ ), and to report laissez-faire behaviors of bottle propping $(\mathrm{p}=0.008)$ and watching TV while feeding $(\mathrm{p}=0.003)$ (Table II).

In adjusted analyses, parents with low health literacy had about twice the odds of reporting that they fed more formula than breast milk (Table III). Parents with low health literacy also had approximately twice the odds of reporting that they would immediately feed when their infant cries, and bottle propping. Watching TV while feeding was not associated with health literacy in adjusted analyses. 
In unadjusted analyses, there was no difference in TV watching by health literacy level (Table II). Parents with low health literacy were more likely to report less than 30 minutes of daily tummy time ( 85.9 vs. $63.6 \%$; $\mathrm{p}<0.001)$.

In adjusted analyses (Table III), parents with low health literacy had a nearly 2 times the odds of reporting that their infant watched any TV. Having low health literacy was also independently associated with a 3 times higher odds of reporting inadequate daily tummy time.

\section{DISCUSSION}

Consistent with prior studies, ${ }^{19}$ we found that parents with low health literacy were significantly more likely to formula feed their children. This finding suggests that use of a health literacy-sensitive approach in counseling parents regarding breast and formula feeding may be beneficial as an obesity prevention strategy during early childhood. Such an approach should be informed by additional study to examine why parents with low literacy are more likely to give formula, including exploring whether information regarding the benefits of breastfeeding need to be more clearly presented, or whether additional support and information is needed to empower parents with low health literacy to continue to breastfeed upon returning to work.

Parents with low health literacy were also more likely to report higher prevalence of some pressuring and laissez-faire feeding behaviors, which may increase a child's risk for obesity. ${ }^{10,19,29}$ Greater provider counseling regarding the potential negative effects of controlling and laissez-faire type feeding practices may be needed during well-child visits, with a particular focus on parents with low health literacy. Recommendations regarding counseling strategies will need to be informed by studies examining why parents with low health literacy may choose a controlling or laissez-faire type feeding practice over feeding practices that are more responsive to a child's cues.

Overall, the prevalence of sweet drink provision and early introduction of solids was low, with no differences by health literacy. This low prevalence may be due to the young age of the children at the time of the assessment, at the 2 month well-child visit. Further assessment of parent provision of sweet drinks and early introduction of solids is clearly indicated at later time points during infancy, as both practices have been strongly associated with the development of obesity. ${ }^{7,8}$

Parents with low health literacy in our study were more likely to report TV watching by their infant. Although few studies have investigated the association between TV and obesity in 2 month olds, TV viewing has been found to have obesogenic effects in both preschool and young adult populations. ${ }^{30}$ The association between infant TV viewing and low parent health literacy suggests a need to enhance and reinforce early messages about reducing TV exposure. Further study regarding barriers to reducing TV watching among parents with low health literacy would be helpful in tailoring these messages so that they are most effective.

Parents with low health literacy in our study also reported less daily tummy time. We recognize that there has been limited study of tummy time and future obesity. Additional study is needed to explore barriers to increasing tummy time among parents with low health literacy, including examining whether and how recommendations are given.

The rationale for why parents with low health literacy reported more obesogenic practices is unclear. Parents with low health literacy may have less access to reliable infant care health information, or may be less likely to understand or act on verbal and written infant care recommendations they encounter within and outside of the healthcare setting. Why certain 
obesogenic behaviors were associated with low health literacy and others were not also is unclear. This issue deserves further study. These findings of health literacy-specific disparities were remarkable because they were noted across multiple low-income, ethnic minority populations that already suffer from disproportionate child health risks. Additional study, including qualitative work, is clearly needed to further examine the mechanisms involved in the link between health literacy and obesogenic behaviors, as well as to determine how to best intervene on individual obesogenic practices.

This study has several limitations. This was a cross-sectional study, and our ability to make conclusions regarding causation is limited. In addition, this study relied on parent selfreport, which is subject to social desirability bias. Even though we examined specific behaviors associated with feeding styles taken from the IFSQ, we did not use the complete scale, ${ }^{22}$ and we therefore cannot make assumptions about the relationship between parent health literacy and entire feeding style constructs. We recognize that we examined a limited number of potentially obesogenic parenting practices, and that there is not uniform agreement regarding the level of risk of the different parenting practices we assessed in this study; these were exploratory analyses. Our assessment of health literacy categorized a relatively small proportion of parents in these low-income communities as having low health literacy, as measured by the STOFHLA. We chose the STOFHLA for a number of reasons: (1) it is one of the most commonly used health literacy assessment tools; (2) performance on the TOFHLA has been strongly tied to health outcomes; and (3) because it tests comprehension, rather than word recognition. ${ }^{25}, 26$ Although some have suggested that existing STOFHLA cut-offs lead to an underestimation of the rate of low health literacy among younger adults, ${ }^{35}$ existing cut-offs are still thought to be useful, with those categorized as having low health literacy considered to be at particular risk for worse health outcomes. Other health literacy assessments, including the more recently developed Newest Vital Sign (NVS) ${ }^{26}$ and Parent Health Literacy Activities Test (PHLAT) ${ }^{35}$ have had limited study as they relate to health outcomes. We recognize that health literacy is a complex construct to measure, as it encompasses reading comprehension as well as numeracy, oral literacy, and navigational skills. No established health literacy assessment measures all aspects of health literacy. Although performance on the STOFHLA is based on understanding reading comprehension passages, it is considered a good proxy measure for health literacy, with good construct validity. Even though we included a number of covariates in our regression models, such as child care outside of the home as well as indicators of access to nutrition and activity counseling (eg, WIC participation, health insurance), we were unable to include all variables that could potentially be associated with obesogenic parenting practices (e.g. parental depression); given our sample size, including too many variables might lead to overfitting of the model. We included in our regression models only covariates that we believed were most strongly associated with the outcomes under study, and as such residual confounding remains a concern. We also focused on the relationship between parent health literacy and obesogenic practices, and did not present findings regarding individual covariates and their relationship to obesogenic practices. Finally, this study was conducted in 4 academic hospitals with a high percentage of minority and low SES families, and therefore our results may not be generalizable.

Our findings demonstrate a link between parent health literacy and some potentially obesogenic infant feeding and physical activity practices, suggesting that there may be a need for the development and evaluation of obesity prevention interventions that target families with limited health literacy skills with a focus on specific high risk behaviors. 


\title{
Acknowledgments
}

Supported by National Institutes of Health (NIH) / National Institute of Child Health and Human Development (R01 HD049794), NIH / National Center for Advancing Translational Sciences (U54 RR023499), the UNC CTSA (UL1RR025747), and the KiDS of NYU Foundation. H.S.Y. is supported by the Robert Wood Johnson Foundation Physician Faculty Scholars Program and HRSA (12-191-1077- Academic Administrative Units in Primary Care). R.S. was supported for her work as part of the NYU School of Medicine Department of Pediatrics Medical Student Summer Research Fellowship Program.

We thank co-investigators Anna Maria Patino Fernandez, PhD, Alan L. Mendelsohn, MD, Benard Dreyer, MD, Asheley C. Skinner, PhD, as well as research coordinators Andrea J. Bacchus, BA, Joanne Finkle, JD, RN, Beth Throop, BA, Lucila Bloise, BA, and Daniela Quesada, BA, MPH, and our entire research staff, for their assistance.

\section{ABBREVIATIONS USED}

\author{
STOFHLA Short Test of Functional Health Literacy
}

TV television

\section{References}

1. Ogden CL, Carroll MD, Curtin LR, Lamb MM, Flegal KM. Prevalence of High Body Mass Index in US Children and Adolescents, 2007-2008. JAMA : the journal of the American Medical Association. 2010; 303:242-9. [PubMed: 20071470]

2. Ogden, Cl; Carroll, MD.; Kit, BK.; Flegal, KM. Prevalence of obesity and trends in body mass index among us children and adolescents, 1999-2010. JAMA : the Journal of the American Medical Association. 2012; 307:483-90. [PubMed: 22253364]

3. Nader PR, O'Brien M, Houts R, Bradley R, Belsky J, Crosnoe R, et al. Identifying Risk for Obesity in Early Childhood. Pediatrics. 2006; 118:e594-e601. [PubMed: 16950951]

4. Leunissen RW, Kerkhof GF, Stijnen T, Hokken-Koelega A. Timing and tempo of first-year rapid growth in relation to cardiovascular and metabolic risk profile in early adulthood. JAMA. 2009; 301:2234-42. [PubMed: 19491185]

5. Ben-Shlomo Y, McCarthy A, Hughes R, Tilling K, Davies D, Davey Smith G. Immediate Postnatal Growth Is Associated With Blood Pressure in Young Adulthood. Hypertension. 2008; 52:638-44. [PubMed: 18768401]

6. Arenz S, Ruckerl R, Koletzko B, von Kries R. Breast-feeding and childhood obesity-a systematic review. Int J Obes Relat Metab Disord. 2004; 28:1247-56. [PubMed: 15314625]

7. Welsh JA, Cogswell ME, Rogers S, Rockett H, Mei Z, Grummer-Strawn LM. Overweight Among Low-Income Preschool Children Associated With the Consumption of Sweet Drinks: Missouri, 1999-2002. Pediatrics. 2005; 115:e223-e9. [PubMed: 15687430]

8. Seach KA, Dharmage SC, Lowe AJ, Dixon JB. Delayed introduction of solid feeding reduces child overweight and obesity at 10 years. Int J Obes. 2010; 34:1475-9.

9. Gross R, Mendelsohn A, Fierman A, Messito M. Maternal controlling feeding styles during early infancy. Clinical Pediatrics. 2011; 50:1125-33. [PubMed: 21757773]

10. DiSantis KI, Hodges EA, Johnson SL, Fisher JO. The role of responsive feeding in overweight during infancy and toddlerhood: a systematic review. Int J Obes. 2011; 35:480-92.

11. Hoerr S, Hughes S, Fisher J, Nicklas T, Liu Y, Shewchuk R. Associations among parental feeding styles and children's food intake in families with limited incomes. International Journal of Behavioral Nutrition and Physical Activity. 2009; 6:1-7. [PubMed: 19123927]

12. Li R, O'Connor L, Buckley D, Specker B. Relation of activity levels to body fat in infants 6 to 12 months of age. J Pediatr. 1995; 126:353-7. [PubMed: 7869191]

13. Committee on Public Education. Children, Adolescents, and Television. Pediatrics. 2001; 107:423-6. [PubMed: 11158483]

14. Laughlin J, Luerssen TG, Dias MS. The Committee on Practice and Ambulatory Medicine-Section on Neurological Surgery. . Prevention and Management of Positional Skull Deformities in Infants. Pediatrics. 2011; 128:1236-41. [PubMed: 22123884] 
15. Huizinga MM, Pont S, Rothman RL, Perrin E, Sanders L, Beech B. ABC's and 123's: Parental Literacy, Numeracy, and Childhood Obesity. Obes Manag. 2008; 4:98-103. [PubMed: 19865608]

16. DeWalt DA, Hink A. Health Literacy and Child Health Outcomes: A Systematic Review of the Literature. Pediatrics. 2009; 124:S265-S74. [PubMed: 19861480]

17. Rothman RL, Housam R, Weiss H, Davis D, Gregory R, Gebretsadik T, et al. Patient Understanding of Food Labels: The Role of Literacy and Numeracy. American Journal of Preventive Medicine. 2006; 31:391-8. [PubMed: 17046410]

18. Selden, CR.; Zorn, M.; Ratzan, S.; Parker, RM. Health literacy. Bethesda, Md. (8600 Rockville Pike, Bethesda 20894): U.S. Dept. of Health and Human Services, Public Health Service, National Institutes of Health, National Library of Medicine, Reference Section; 2000.

19. Kaufman H, Skipper B, Small L, Terry T, McGrew M. Effect of Literacy on Breast-feeding Outcomes. Southern Medical Journal. 2001; 94:293-6. [PubMed: 11284516]

20. Oettinger MD, Finkle JP, Esserman D, Whitehead L, Spain TK, Pattishall SR, et al. Color-coding improves parental understanding of body mass index charting. Academic Pediatrics. 2009; 9:330 8. [PubMed: 19679524]

21. Harris PA, Taylor R, Thielke R, Payne J, Gonzalez N, Conde JG. Research electronic data capture (REDCap) - A metadata-driven methodology and workflow process for providing translational research informatics support. Journal of Biomedical Informatics. 2009; 42:377-81. [PubMed: 18929686]

22. Thompson AL, Mendez MA, Borja JB, Adair LS, Zimmer CR, Bentley ME. Development and validation of the Infant Feeding Style Questionnaire. Appetite. 2009; 53:210-21. [PubMed: 19576254]

23. Comm on Pub. Educ. Children, Adolescents, and Television. Pediatrics. 2001; 107:423-6. [PubMed: 11158483]

24. Baker DW, Williams MV, Parker RM, Gazmararian JA, Nurss J. Development of a brief test to measure functional health literacy. Patient Education and Counseling. 1999; 38:33-42. [PubMed: 14528569]

25. Berkman, ND.; DeWalt, DA.; Pignone, MP.; Sheridan, SL.; Lohr, KN.; Lux, L., et al. Evidence Report/Technology Assessment No. 87. 2004. Literacy and Health Outcomes.

26. Berkman, ND.; Sheridan, SL.; Donahue, KE.; Halpern, DJ.; Viera, A.; Crotty, K., et al. Evidence Report/Technology Assesment No. 199. Agency for Healthcare Research and Quality; 2011. Health Literacy Interventions and Outcomes: An Updated Systematic Review.

27. Harrell, J.; FE. Regression Modeling Strategies with Applications to Linear Models, Logistic Regression, and Survival Analysis. Springer-Verlag; 2001.

28. DeWalt Da PMP. Reading is fundamental: The relationship between literacy and health. Archives of internal medicine. 2005; 165:1943-4. [PubMed: 16186462]

29. Worobey J, Lopez MI, Hoffman DJ. Maternal behavior and infant weight gain in the first year. Journal of Nutrition Education and Behavior. 2009; 41:169-75. [PubMed: 19411050]

30. Andersen RE, Crespo CJ, Bartlett SJ, Cheskin LJ, Pratt M. Relationship of Physical Activity and Television Watching With Body Weight and Level of Fatness Among Children. Jama. 1998; 279:938-42. [PubMed: 9544768]

31. Schillinger D, Piette J, Grumbach K, Wang F, Wilson C, Daher C, et al. Closing the loop: physician communication with diabetic patients who have low health literacy. Archives of internal medicine. 2003; 163:83-90. [PubMed: 12523921]

32. Seligman HK, Wallace AS, DeWalt DA, Schillinger D, Arnold CL, Shilliday BB, et al. Facilitating behavior change with low-literacy patient education materials. Am J Health Behav. 2007; 31:S6978. [PubMed: 17931139]

33. Yin HS, Dreyer BP, van Schaick L, Foltin GL, Dinglas C, Mendelsohn AL. Randomized Controlled Trial of a Pictogram-Based Intervention to Reduce Liquid Medication Dosing Errors and Improve Adherence Among Caregivers of Young Children. Arch Pediatr Adolesc Med. 2008; 162:814-22. [PubMed: 18762597]

34. U.S. Department of Health and Human Services Office of Disease Prevention and Health Promotion. National Action Plan to Improve Health Literacy. 2010. 
35. Kumar D, Sanders L, Perrin EM, Lokker N, Patterson B, Gunn V, et al. Parental Understanding of Infant Health Information: Health Literacy, Numeracy, and the Parental Health Literacy Activities Test (PHLAT). Academic Pediatrics. 2010; 10:309-16. [PubMed: 20674532] 


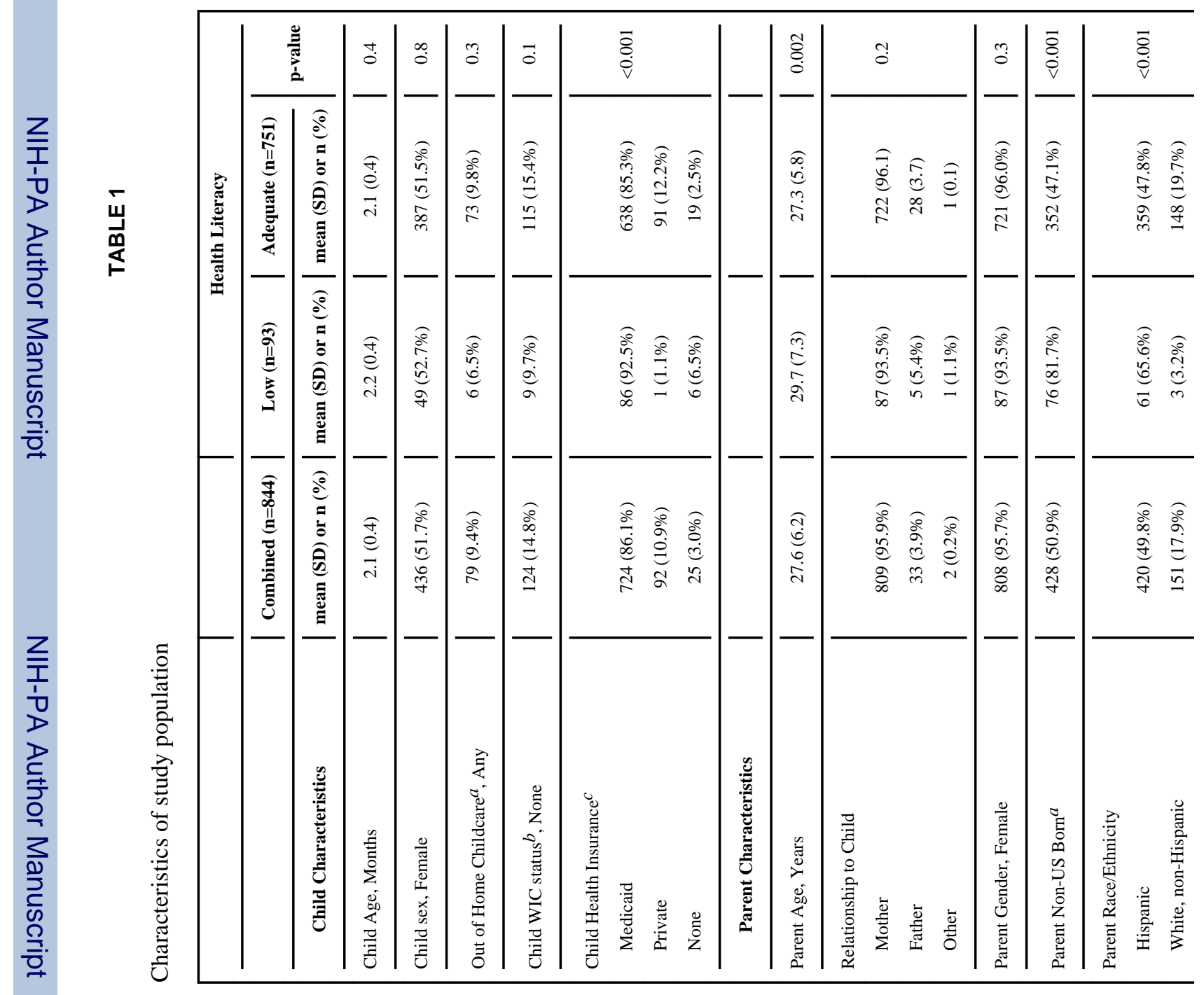




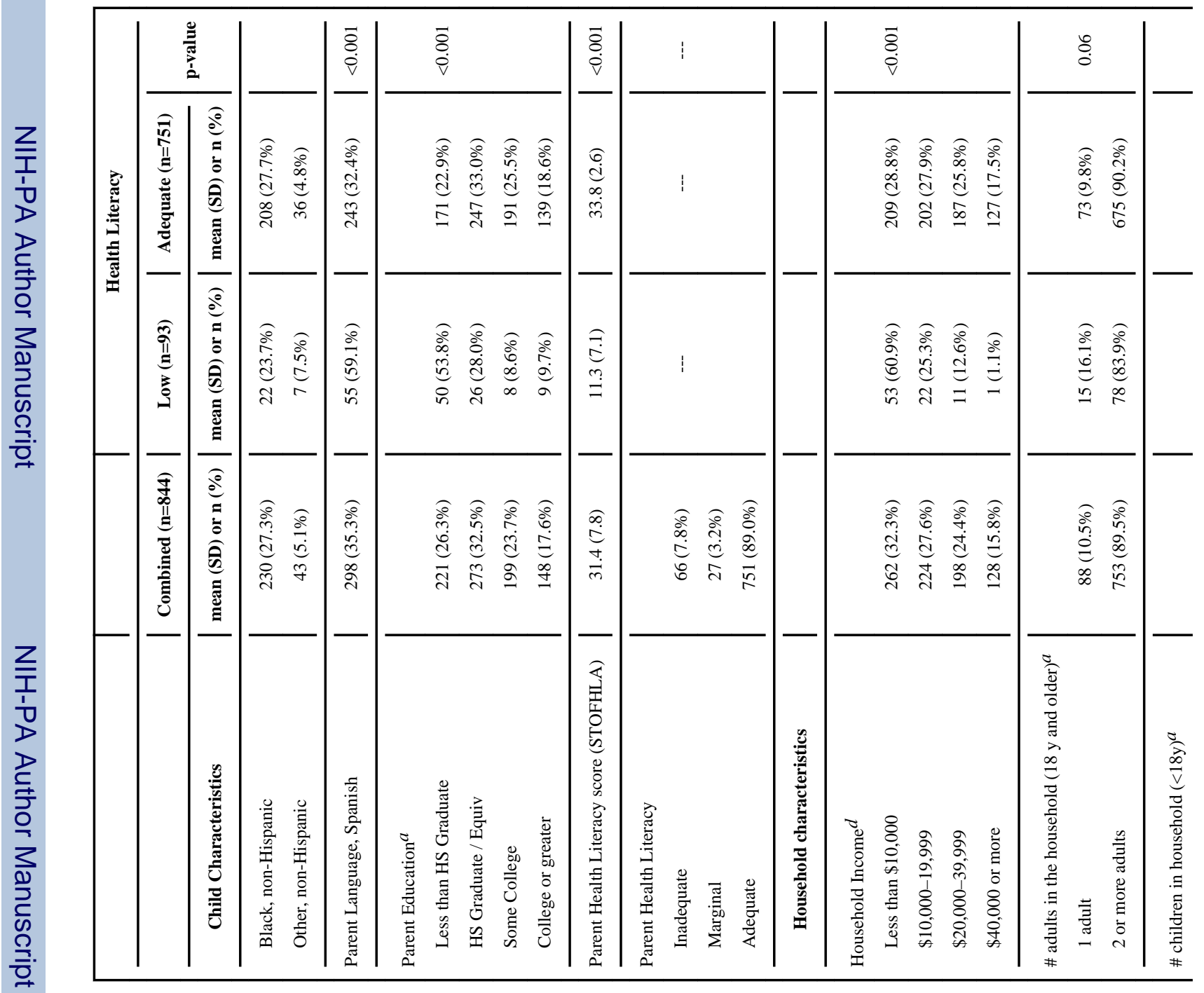

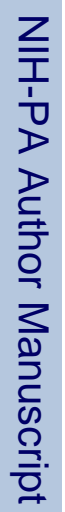




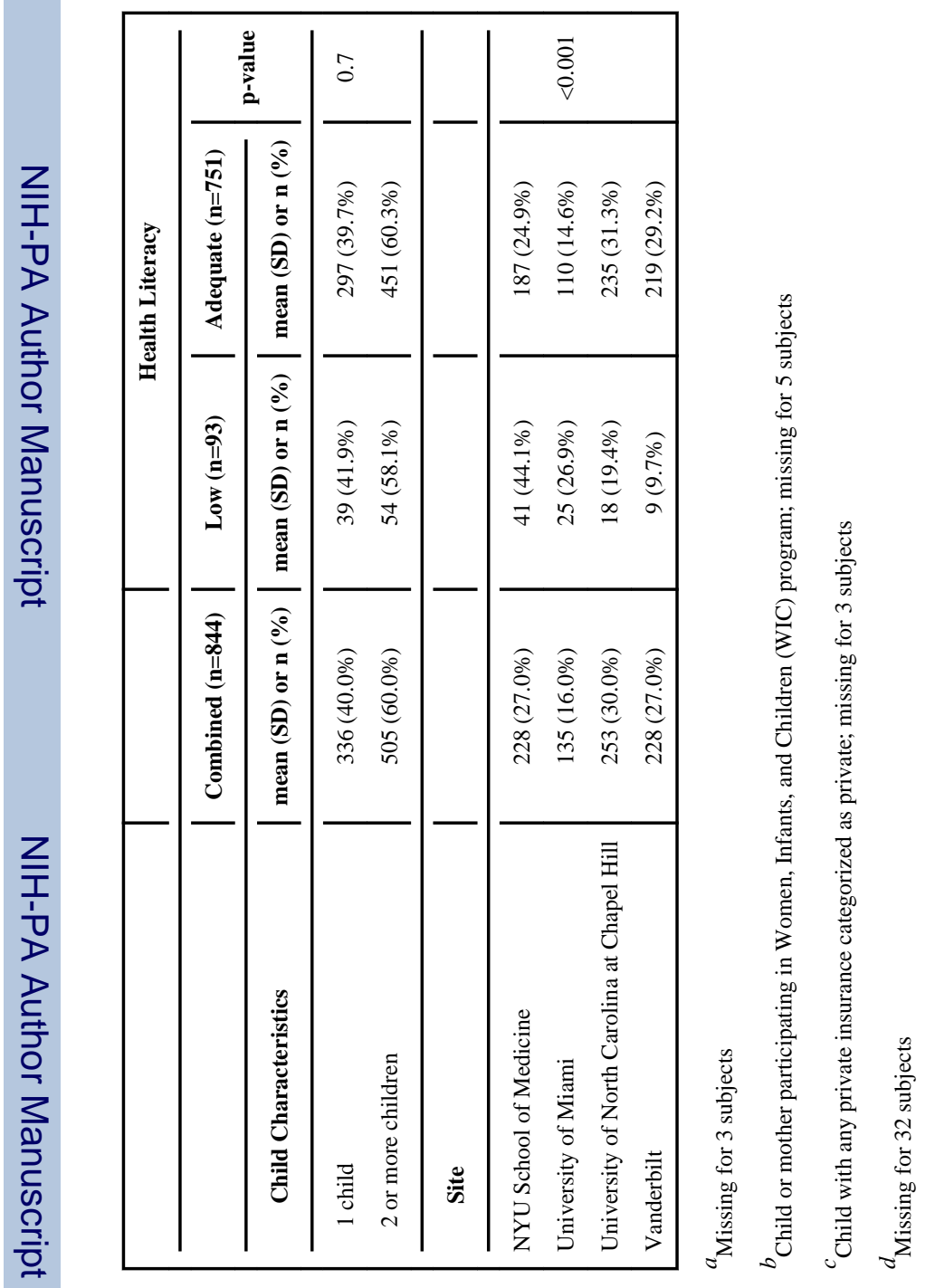

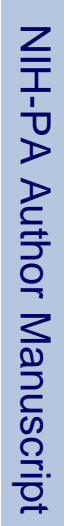




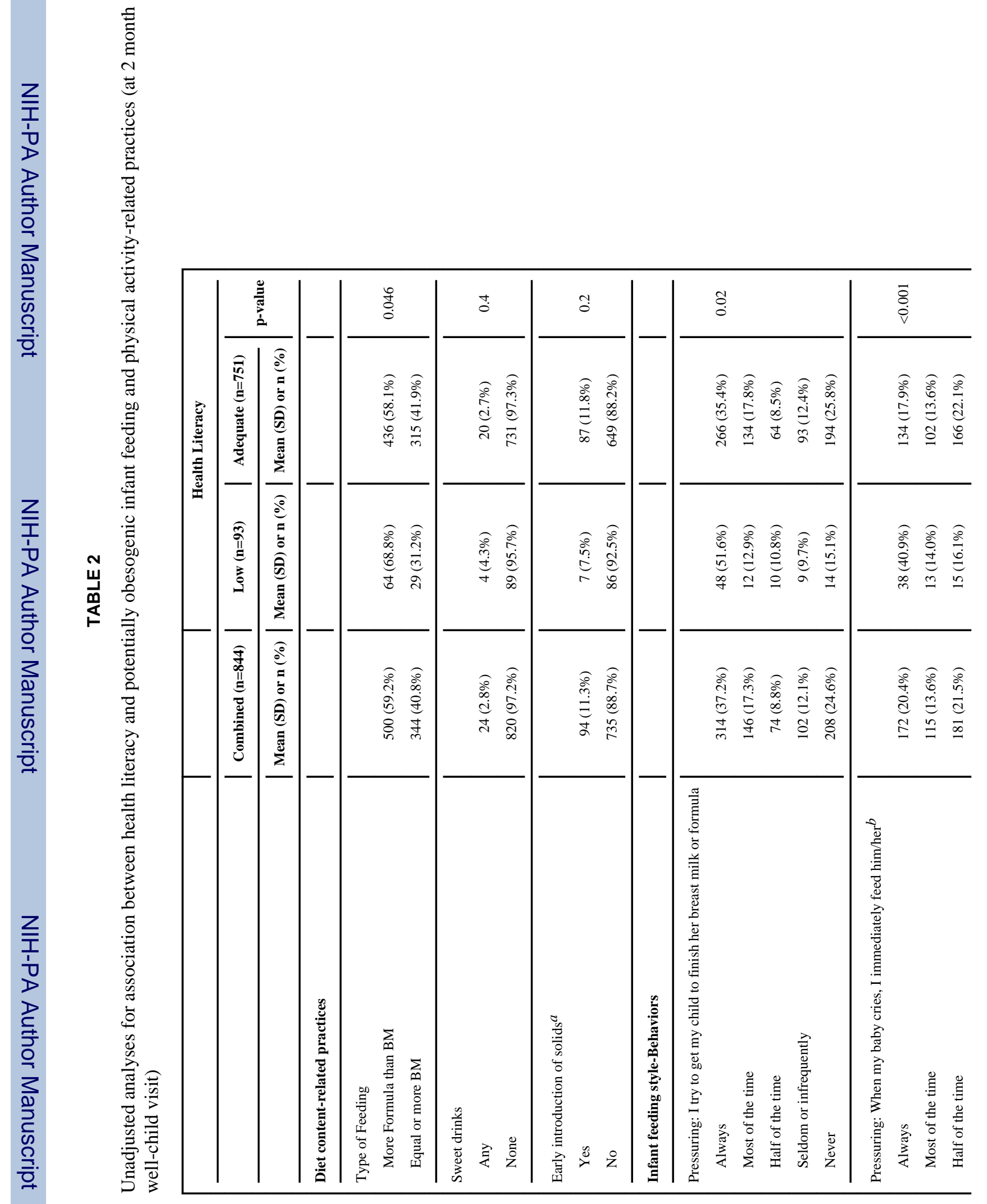




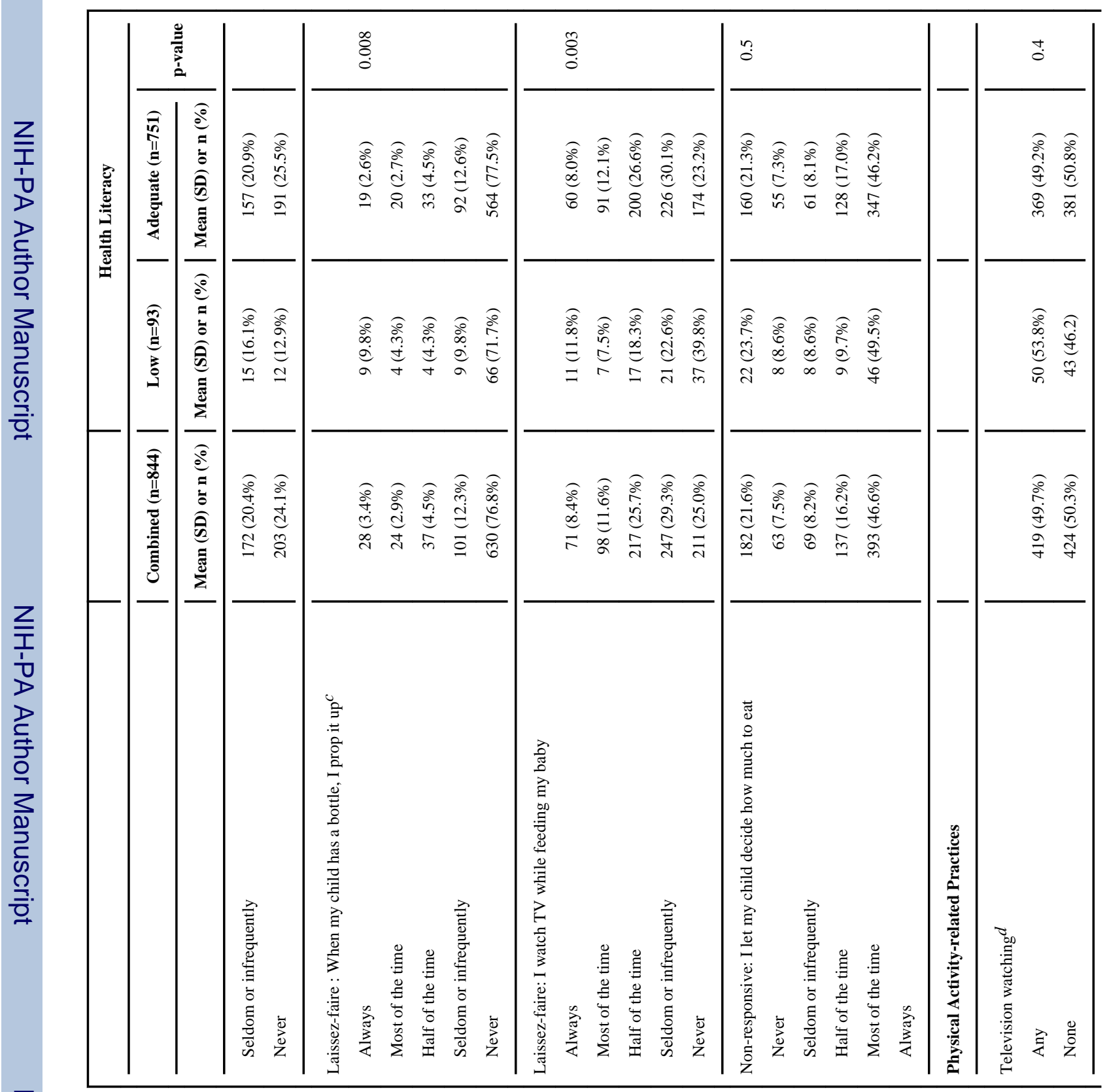

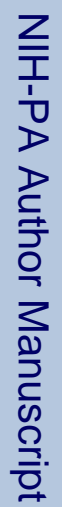




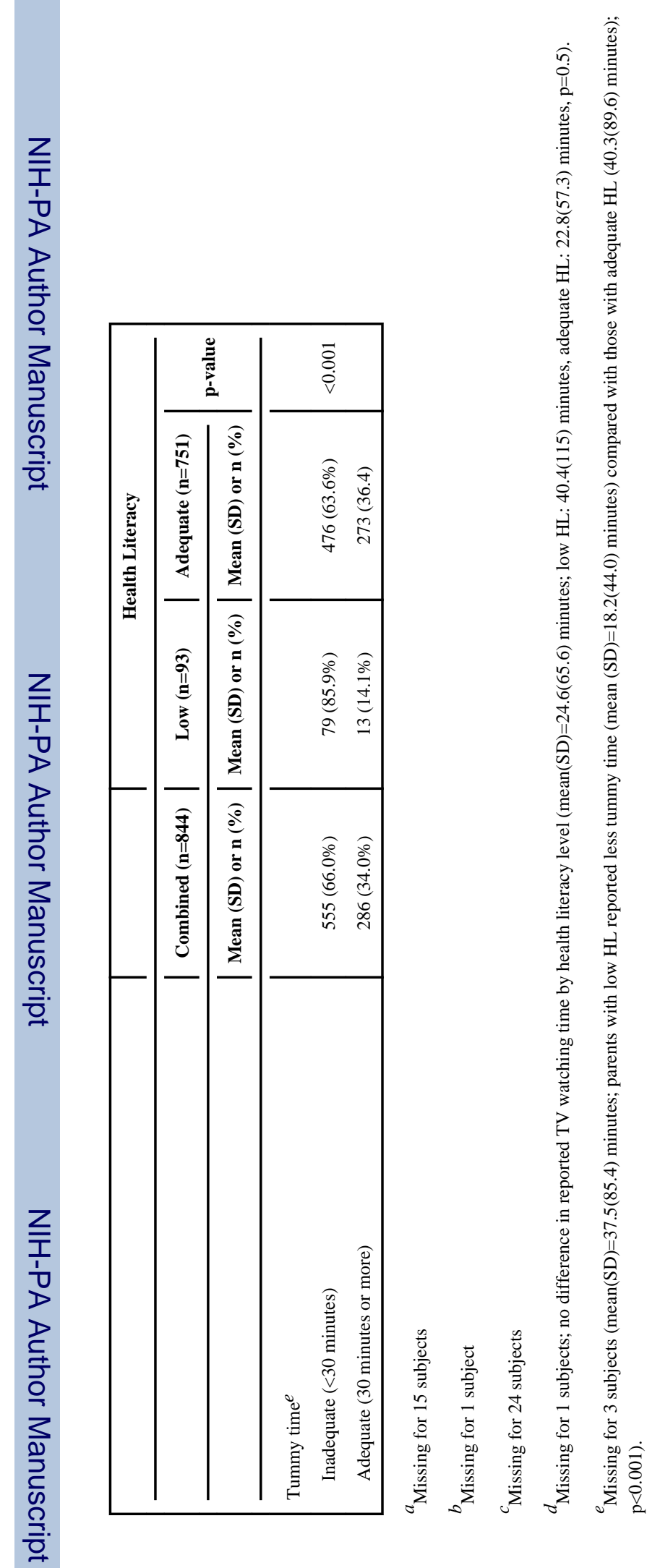

J Pediatr. Author manuscript; available in PMC 2015 March 01. 


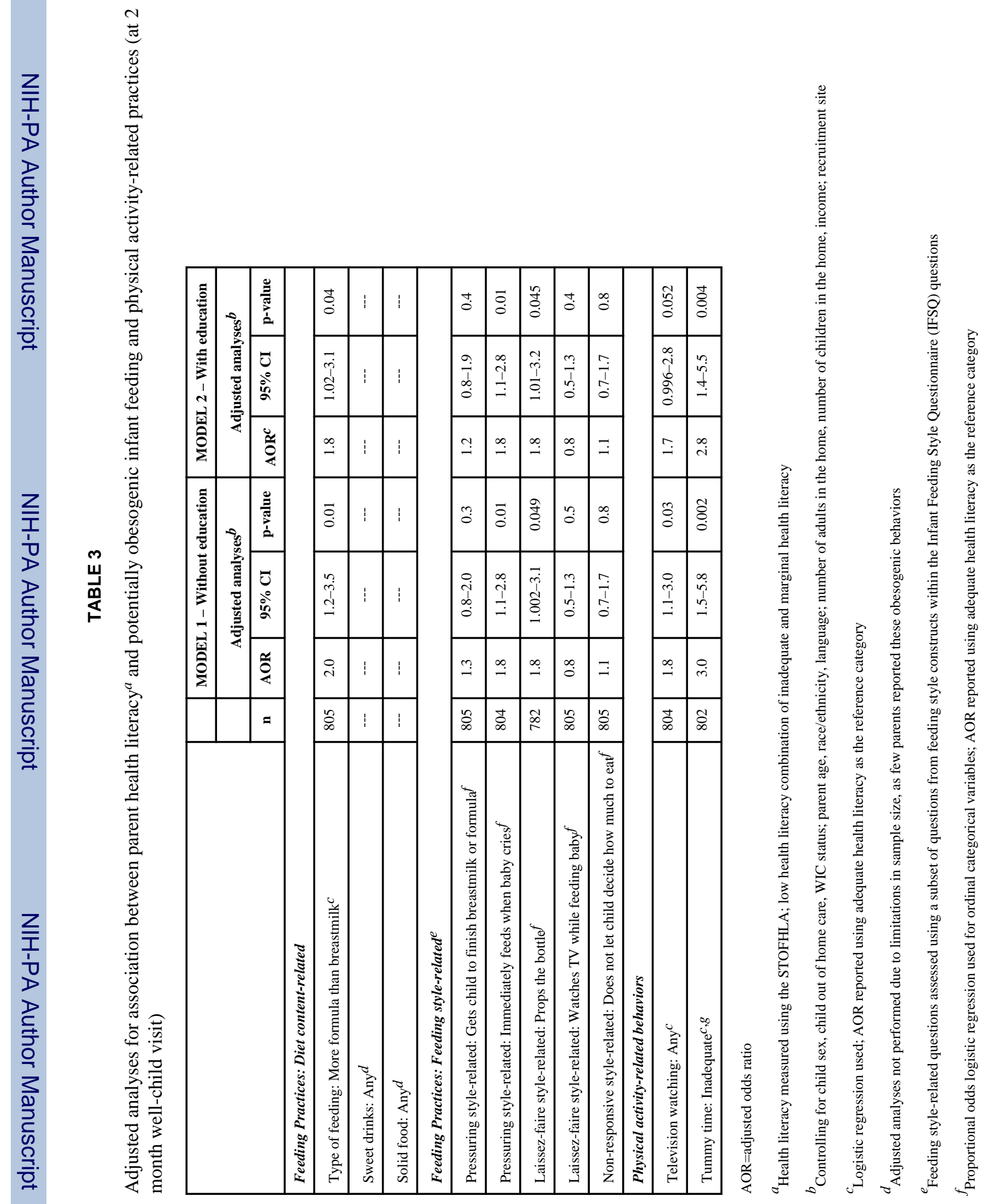


